\title{
HOTÉIS DO SÉCULO XIX EM SÃO PAULO E NO RIO DE JANEIRO Diversidade de Serviços
}

\author{
Mário Jorge Pires*
}

\begin{abstract}
RESUMO: A partir da vinda da Família Real e com a gradativa mudança do eixo econômico do nordeste açucareiro para a região sudeste, com a expansão da lavoura cafeeira, começaram a surgir os primeiros estabelecimentos hoteleiros que se distinguiam das simples hopedarias. Permanecem desconhecidos, porém, os tipos de serviços que eram oferecidos e a quem eram dirigidos. Este pequeno estudo procura esclarecer parte destas questões, mostrando que o pernoite representava apenas uma das opções no quadro geral dos serviços destes pioneiros.
\end{abstract}

UNITERMOS: Hotelaria: história; Rio de Janeiro; São Paulo. Serviços hoteleiros: permoite; restaurantes; festas.

ABSTRACT: Since the arrival of the Portuguese Roval Family and with the gradual change in the Brazilian economic axis, from Northeast sugar-producer to the South-West area, with the expansion of coffee plantations, there have appeared the first hotels - different of simple lodging-houses - in Brazil. But all kinds of senices offered by these stablishments and who it was for, still remain unknown. This small work tries to explain part of the question, proving that night-spents were only one of the options offered by these pioncers.

KEY-WORDS: Hotel-business: histon; Rio de Jameiro; São Paulo. Hotel services: night-spents; restaurants; partys.

\section{INTRODUÇÃO}

O aparecimento dos primeiros hotéis de categoria no Brasil prende-se ao crescimento das cidades e ao desenvolvimento dos segmentos médios da população. Neste sentido, o século XIX apresentou importantes fatores históricos, que facilitaram a ocorrência destes fenômenos.

(*) Mestre em Ciências da Comunicação pela Escola de Comunicações e Artes da USPP. Prof. Assistente do Departamento de Relações Públicas. Propaganda e Turismo da
ECAUSP End. para correspondência: Rua Nicolau Piratininga, 72 - CEP 03643 - São Paulo -
Brasil. 
A vinda da Família Real, em 1808, não representou apenas um grande marco político no processo de emancipação do Brasil. Findos os desarranjos que a presença de tal contingente provocou, num primeiro momento, a cidade do Rio de Janeiro passou a contar com uma série de novos serviços antes desconhecidos da população, embora se reconheça que, durante bom tempo, sua amplitude e seu grau de eficiência estiveram muito aquém das necessidades da época.

De qualquer forma, foi neste período de crescimento que surgiram os primeiros hotéis de categoria. Não é intenção, neste breve estudo, abordar o empolgante tema das hospedarias, das casas de pasto, das estalagens e dos pousos, pois o volume de fontes históricas e a abrangência do assunto demandariam uma pesquisa mais extensa que não poderia aqui ser apresentada. Antes, discute-se quais os serviços oferecidos por estes pioneiros, que ênfase era dada à cada um deles e, por último, quem os procurava.

\section{HOTÉIS DO SÉCULO XIX NO RIO DE JANEIRO}

\subsection{Carência de Alojamentos}

A palavra hotel, embora não fosse desconhecida no Rio de Janeiro na primeira década do século passado, talvez não passasse de um eufemismo para designar uma simples estalagem. Luccock, um dos primeiros viajantes do século XIX, não nos fala propriamente de hotéis; apenas uma breve menção nos seus relatos de que fora informado pelo gerente e pelo copeiro do hotel ${ }^{1}$, mas é bem possível que o termo tenha sido usado indevidamente, pois tanto este viajante quanto outros do mesmo período, não mencionaram nada neste sentido.

Nestes primeiros tempos em que o Rio de Janeiro se transformara cm sede do Reino-Unido, o mais provável é que realmente não houvesse nenhum hotel tal qual seria, depois, concebido anos mais tarde. Compreende-se, assim, que a partir desta deficiência, tenham os alugueis das casas chegado a preços extravagantes, pois a quantidade de estrangeiros chegados deve ter provocado muitos transtornos numa cidade que em praticamente quase tudo estava mal preparada para "ecebê-los

A carência de hospedagem na Corte estendeu-se por décadas afora e a instalação dos primeiros hotéis de fato parece não ter resolvido a questão, pois o pastor americano Kidder, já no adiantado ano de 1837, se surpreende com a escasse\% de hospedarias e casas de pasto, manifestando-se nos seguintes termos:
Existcm alguns hotéis franceses $c$ italianos com restaurantes e quentos para cilugar: que sāo sustcntados principalmente pelos muncrossos estrangeiros cen trûnsite ou tesidindo temporariamente no lugar. Entretante, para senvir os riajantes nacionais he soinente oito ou dez estalagens cm toda a cidade, ctuja populaçào monta a duzento. mil habitantes, sendo que poucas delas excedem os limites de umn casa de fumilia comum. ${ }^{3}$

\subsection{Precedência do Rio de Janeiro}

Tarefa difícil é saber, com precisāo, o momento em que a estalagem e o hotel começaram a se distanciar um do outro. O Rio de Janciro, neste caso, teve a precedência, pois se constata através do já citado depoimento de Kidder a presença de "alguns hotéis franceses e italianos" 2 distintos, ao que parece, das hospedarias. É de crer, portanto, que já na década de 1830 os hotéis da capital apresentassem um tipo de serviço diferenciado. Para o final da década scguinte, verifica-so com bastante clareza esta constatação, uma vè que a Corte possuía onze hotéis, relacionados pelo Almanaque de 1849 na mesma coluna das chamadas "casas de pasto". 3

Em São Paulo, a quantidade de estabelecimentos que levava nome de hotel era bem inferior à da Corte, mesmo uma década mais tarde, pois o Almanaque de 1858 mostra a existência de seis deles Nem todos, contudo, ofereciam hospedagem, apesar do nome: alguns apenas designavam cafés e bilhares. O Hotel Recrcio Paulistano tinha bilhares, mas não consta que hospedasse viajantes, pelo menos nesta época. Os hotéis Paulistano e Universal tinham bilhares c davam hospedagem, enquanto o Hotel des Voyageurs apenas dava hospedagem Além destes, havia o Café e Hotel do Commercio, que nada informa, e o Geryn, oferecendo apenas bilhares. ${ }^{4}$

Conclui-se, assim, que o Rio de Janciro apresentou realmente uma precedência quanto à introdução de hotéis no sentido mais atualizado da palavra, mas esta dianteira da Corte pouco durou, pois a partir da inauguração da estrada de ferro inglesa, proliferaram estes estabelecimentos na capital paulista, tirando da mentalidade do povo, $\mathrm{cm}$ curto espaço de tempo, a visão pejorativa que levavam, pelo menos quanto à prestação de alguns tipos de serviço bem específicos.

\subsection{Estrangeiros no Ramo}

A presença de estrangeiros no ramo era significativa. porém não exclusiva, tant() no Rio de Janeiro com() em São Paulo. Nesta cidade, dos cinco estabelecimentos que efetivamente levavam o nome de hotc em 1858, dois pelo menos tinham como proprietários nomes de brasileiros ou, talvez, portugueses. No Rio, a presença francesa é bastante 
marcante nessa atividade, não só pelos nomes dos seus proprictários, como os dos estabelecimentos. Para o ano de 1859 encontra-se no Almanaque do Rio de Janeiro uma relação de quarenta e um hotéis e muitos sugerem a origem: Hotel des Frères Provençaux, de Ferdinand Guigou; Hotel Ravot, de Emilio Ghangy ou Hotel Francez. de André Long. Mas havia também o Hotel Allemanha ou o Hotel Uniāo Ihérica - que não informavam quem são os proprietários -, o Hotel Brasileiro, de Manuel Correa Pinto, ou o Hotel dos Coelhos, de José Joaquim Coelho da Costa e Filhos. ${ }^{5}$

\section{HOTÉIS DO SÉCULO XIX EM SÃO PAULO}

\subsection{Relativo Atraso de São Paulo}

No que concerne ao aspecto quantitativo, São Paulo ainda estava atrás do Rio de Janeiro em termos de número de estabelecimentos na década de 1870 . Para o ano de 1875 , possuía a Corte sessenta hotéis e vinte e duas hospedarias. Embora não obtendo os dados da capital paulista nesse mesmo ano, sabe-se que $\mathrm{cm} 1878$ esta integrava () total de vinte e um hotéis e treze hospedarias, arroladas pelo Indicador de São Paulo juntamente com as "casas de pasto". 6

Houve circunstâncias que influenciaram negativamente o surgimento de hotéis na paulicéia. Por volta de meados do século passado, o desenvolvimento da província ainda tinha sido insuficiente para modificar significativamente a capital, que se mantinha arraigada a antigos costumes. Conforme notou Affonso de Freitas, os paulistas de entâo não tinham ânimo de se hospedarem em hotéis e os que o fizessem seriam irremediavelmente lançados no índex da suspeição por imoralidade e todas as portas se lhes cerrariam, evitando-lhes o contato.

A vida coletiva dos hoteis feria a suscetibilidade da populaçào, com o aspecto de uma promiscuidade perigosa e intolcrárel, incompatínel corn o regime de tucanho recato, cheio de reservas c retraimentos que só se abrandara após largo periodo de convívio e de adquirida estreita amizade.

Diz ainda Affonso de Freitas que a partir de 1862 é que começaram a aparecer em São Paulo estabelecimentos verdadeiramente dignos daquela classificação, pois antes, ainda que muitas casas se intitulassem hotéis, nāo passavam, todavia, de meras estalagens. Foi nas proximidades desta data que se instalaram os hotéis da Itália, da Europa, do Globo, entre outros. ${ }^{7}$

\subsection{Hóspedes}

É um engano porém pensar que o surgimento dos hotéis em São) Paulo deu-se pela presença dos fazendeiros de café da cidade. Tanto aqui como no Rio de Janeiro, eram raros os potentados rurais que se hospedavam em hotéis pois, seguindo a tradição - de modo geral brasileira -, os fazendeiros possuíam várias casas: além daquela construída na cidade onde se encontravam suas fazendas, possuíam uma na capital, usada em ocasiōes especiais: festividades como Natal e outros dias santos, ou mesmo na época do nascimento dos filhos; mais tarde, para militância política e acompanhar negócios urbanos.

Quem, entâo, utilizava os primeiros hotéis?

Uma propaganda publicada no Almanaque de 1858 mostra o estabelecimento de um hotel preocupado em oferecer um bom serviço aos viajantes, tanto nacionais como estrangeiros, através do seguinte texto:

\section{HOTEL DES VOYAGEURS}

CASA DE SOTEAA - PROXIMO Á ACADEMIA

Pedro Imbert, tem a honra de participar ao respeitúrel público, e cm particular a seus amigos, que estabeleceu cm a cidade de S. Paulo, um hotel denominado - Hotel de. Voyageurs - onde os srs. viajantes, tanto nacionais como estrangeiros, encontraraio sempre todo o bom acolhimento, $e$ a mais agradárcl hospedagem.

O local deste novo hotel, é sem dívida, um dos mais agradaveis, nào só pela excelene vista que ofcrece a "sotéa", mas ainda pela salubridade do lugar além de ficar no centro da cidade.

Ninguém contestará que uma das primeiras necessidades $\mathrm{cm}$ os estabelecimcntos desta ordem, é uma bem dirigida e acéada cozinha, e neste sentido, o proprictúrio se ufana de haver feito a melhor aquisição a desejar, pois tem incumbido a direçùo do mesma a um hábil c "provecto" chefe, que outrora jú ocupou este luzar, em alghtmas das principais casas de aristocracia curopćia. O proprictário, nào tem poupado esforços e despesas a fim de tornar o seu estabelecimento digno da concorrencia do. srs. viajantes, oferecendo-thes a maior soma de comodidades, com o menor dispéndio possivel."

De fato, nos primeiros hotéis que se instalaram em São Paulo só se hospedavam forasteiros-viajantes não suficientemente importantes a ponto de serem recebidos nas residências da elite local. P(or esta ép()ca (meados do século XIX), nāo se tem registro de viagens de la\%er à capital da província. Fréderic Houssay, utilizando-se de um destes hoteis em 1862, diz que estavam povoados de negociantes estrangeiros, que falavam todas as línguas. ${ }^{8}$ 


\section{DIVERSIDADE DOS SERVIÇOS}

Contando apenas com viajantes na condição de hóspedes, desenvolveram os hotéis alguns tipos de serviço que contaram com amplo sucesso. No Rio de Janeiro os banhos de mar e, ao que parece, em maior escala, os de água doce.

A ligação entre os banhos salgados ou minerais, com propriedades medicinais e, por isso, indicados para a cura de diversos males era, a bem da verdade, um fenômeno mundial. No entanto, no caso da Corte, os habitantes e mesmo a população flutuante tinham bons motivos para temer pela saúde, pois a febre amarela começou a ganhar muita amplitude depois de 1850; a peste bubônica já havia chegado por meio dos ratos que viajavam nos poróes dos navios estrangeiros, enquanto a varíola também atingiu a cidade em virtude das migrações internas.

Seu crescimento desordenado teve como preço a total falta de infra-estrutura para atender ao mínimo serviço de higiene. Nas últimas décadas do século a situação piorou, transformando as ruas e as praças numa imensa feira, onde a higiene era nenhuma: os insetos infestavam os quiosques imundos que vendiam café, cachaça, broas, lascas de bacalhau, sardinhas e muitas outras perigosas miudezas comestíveis. $O$ Rio de Janeiro não pôs termo aos seus graves problemas de higiene senão no início deste século, no governo de Rodrigues Alves, cujo programa limitava-se quase que exclusivamente ao saneamento e melhoramento do porto. Para isso contou o presidente com o prefeito Pereira Passos, munido de amplos poderes, e com o sanitarista Oswaldo Cruz.

Estas razões contribuíram, sem dúvida, para a popularidade dos banhos de mar ou de cachoeiras de águas férreas, que também foram se tornando muito apreciados na época. Ao que parece, ainda no final da década de 1850 , o banho de mar já havia se tornado um comércio bastante explorado. O Almanaque Laemmert traz um interessante anúncio que revela, entre outras coisas, a sofisticação que foi assumindo este novo hábito:

\section{CABANAS ROMÂNTICAS}

Salas e Gabinetes mobiliados, entre arbustos, caramanchões, relvas e flores, próximos à praia de banho e ponte das barcas, senvidos por pagem e cozinheiro ao toque da campainha. Estes aposentos reunem em si tudo quanto é necessário a umna pessoa solteira ou casal sem filhos, como mobílias, roupa de carna e do rosto, água para banho etc. etc. Há todo o desvelo pela conservação do asseio, pela prontidào do serviço, e só se admitem pessoas bem morigeradas. As condiçōes acham-se impres$\operatorname{sas}(\ldots)^{5}$
Os poucos banhos de água doce existentes eram, curiosamente, explorados também - porém não exclusivamente - por hotéis que, desta maneira, procuravam oferecer um atrativo a mais para seus hóspedes. Em 1859, na relação dos serviços prestados no Rio de Janciro, constavam os chamados "banhos públicos". Havia a "Barca dos Banhos", os "banhos da travessa do Bom Jesus" e os "Banhos de Vapor Aromatizados". Os "Banhos da Saúde", entretanto, ficavam no Hotel Pharoux da Rua Fresca e os "Banhos Dreux" no Hotel Ravot". Do mesmo modo, alguns hotéis, como o Belvedere, na Gávea, anunciavam-se com os predicados que lhes dava a natureza: “(...) os hóspedes podem usufruir da chácara com banhos de cachoeira"9.

Além dos "salutares banhos", os hotéis se encarregavam de prestar alguns outros serviços. Encomendar um bom jantar num hotel já era possível na década de 1840 . Os mais aquinhoados, residindo $\mathrm{cm}$ boas casas na cidade, mandavam entregá-lo nos seus próprios solares, recebendo os convivas no velho estilo e, desta forma, preservando toda a privacidade. Assim prova o Almanaque da Corte:

Hotel dos Estrangeiros - Alugam-se quartos e aposentos ricamente mobiliados, e incumbem-se de jantares de encomenda, tanto no recinto do hotel, como nas casas dos prezados clientes. ${ }^{10}$

A encomenda de um jantar muitas vezes implicava na utilização de outros serviços do hotel, uma vez que este também alugava recintos para bailes, funções* e para os próprios banquetes encomendados. É o caso do Hotel de Itália que, segundo o Almanaque de 1849 possuía "local próprio para bailes, jantares e funções"3

Segundo o gosto e o dinheiro do freguês, as festas realizadas nos hotéis podiam contar também com paramentos alugados. Especialista neste serviço era o Hotel do Norte, que incumbia-se de qualquer função, tanto de iguarias como para bailes e alugava tudo o que fosse necessário para o dito serviço. ${ }^{3}$

Além destes serviços, os hotéis de categoria comumente abriam seus restaurantes a quantos quisessem saborear os requintes de suas cozinhas, independentemente de estarem os "gourmets" neles hospedados. Os hoteleiros de então queriam "pegar os hóspedes pelo estômago". A cozinha francesa, tão valorizada nesta época, representava um ponto alto nos atrativos dos bons hotéis. No Hotel des Etrangers, no Catete, anunciava-se "un bon valet de chambre français, connaissant aussi la cousine cherche uns place".

(*) Funçốes, na época, normalmente era empregado para recitais e outras comemorações familiares. 
O Hotel das Quatro Naçōes, de Charles Luc, oferecia "díners et soupers très bien servis à l'heure"; o Hotel de Londres dispunha de cozinheiro francês e mesa redonda às 9 horas e 4 da tarde; no Jardim Botânico abriu-se o Hotel Orleans, com grande baile campestre e dentro do salão grande variedade de comidas e bebidas. ${ }^{9}$

Aos que gozavam de melhores condiçōes econômicas, foi se tornando um hábito almoçar ou jantar nos hotéis. Estes, percebendo o filáo econômico que representava semelhante costume, faziam anunciar nos periódicos seus serviços de comidas e bebidas. Assim, na parte referente aos anúncios pagos do Almanaque Laemmert, constam propagandas como estas:

\section{HOTEL DOS ESTRANGEIROS - RUa D'Assembléia, 69}

Restaurant a la mode de Paris

- Almoço: dois pratos, meia garrafa de vinho, pào e sobremesa - 800

- Jantar: sopa, três pratos, meia garrafa de vinho, pão e sobremesa - $1 \$ 200$

- Pensionistas: $458000^{5}$

Muito comum nos anúncios publicados nestes almanaques era a ênfase que se dava ao primor das comidas e bebidas oferecidas pelos hotéis.

O dono do já citado Hotel do Norte dizia-se sorveteiro de Suas Majestades Imperiais, querendo, com isso, distinguir das demais a sua especialidade culinária. Ano a ano, de anúncio a anúncio, repete-se com bastante freqüência a palavra "iguaria", como na propaganda do Hotel dos Estrangeiros:

O respeitável público encontrará (no hotel) sempre as iguarias mais procuradas no Rio de Janeiro, bem como vinhos, licores, consen'as, frutas etc, etc, por preço o mais cômodo possivel.

Não apenas o Rio de Janeiro possuía bons hotéis. Neste quadro onde surgiram os primeiros estabelecimentos de categoria, merece destaque a instalação, em São Paulo, daquele que foi considerado o melhor hotel do Brasil: o Grande Hotel, inaugurado em 1878. Koseritz, quando de sua estada em São Paulo, nele esteve hospedado e não foi sem entusiasmo que o descreveu:

Chamava-se Grande Hotel e ficara na Rua de Sào Bento, esquina com o beco do Lapa (hoje Rua Miguel Couto), indo até à Rua de São José (Rua Líbcrn Badaró): Este hotel (a casa pertence ao sr. Glete do Rio de Janeiro e foi especialmente consEste hotel (a casa pertence ao sr. Glete do Rio de Janeiro e foi especialmente cons.
truida para o fim a que se destina) Eo melhor do Brasil. Nenhum hotel do Rio se lhe compara. Pertence ao sr. Schorcht, o antigo gerente do 'Germânia' do Rio, o qual dirige magistralmente $\bullet$ seu estabclecimento. Nem o Rio nem todo o resto do Brasi possue nada de parecido em matéria de luxo (no arranjo da casa e dos quar. tos), de senviço excelente, de cozinha magnífica, de variada adega. Grandes candelabros a gás iluminam o vestíbulo, e por uma larga escada de mánnorc branco se sobc ao primeiro andar, onde um empregado de irrepreensivel estilo e toilette, arisado pelo porteiro por campainha elétrica, recebe o recém chegado. Belos quartos com inolo porteiro por campainha elétrica, recebe o recém chegado. Belos quartos com ino-
biliário muito elegante e excelentes camas, gás, banho, correios e telegrafos em casa todas as comodidades, que täo raramente se encontram juntas, existem aqui ao pre fo moderado de $5 \$ 000$ por pessoa, enquanto no Rio hotéis muito piores pedem $8 \mathrm{e}$ $10 \$ 000 .{ }^{11}$

A existência de alguns hotéis de categoria deve ter facilitado o desenvolvimento de viagens de "recreio", mas sobre este assunto escassas são as informaçōes, mesmo porque ainda se tratava de uma minoria os que viajavam por lazer e se utilizavam dos serviços hoteleiros Neste sentido, ganha importância um relato feito por um ex-aluno da Academia de Direito, natural do Rio de Janeiro e que, findado o Curso em 1852, para sua terra partiu, onde se estabeleceu como advogado exercendo, depois, as funçōes de delegado de polícia e juiz municipal. Trata-se de Firmo de Albuquerque Diniz. Trinta anos depois de ter deixado a cidade de São Paulo realizou, em 1882, uma viagem a passeio, constatando as grandes modificaçōes pelas quais passara a capita da província. A respeito, escreveu um opúsculo sob o pseudônimo de Június.

A narrativa mostra muitos aspectos interessantes a respeito da visita. Primeiramente, está Június sufocado pelo calor do Rio, querendo refrescar-se com uma viagem a Petrópolis. Um conhecido, que encontrou por acaso na Rua do Ouvidor, sugeriu-lhe uma viagem a São Paulo onde, além do clima ameno, poderia usufruir de uma cidade com muita animação, muita vida. Aceitando a sugestão, partiu de trem e aqui chegando, hospedou-se no Grande Hotel, com o qual ficou admirado:

O Grande Hotel causou-me agradável impressão: ć um estabelecimento bem montado, e de luxo: na Corte e nas capitais das principais proríncias do Império, que percorri, não se encontra um igual. Inúmeros bicos de gás, bonitos candelabros, lindas jarras de flores sobre as duas compridas mesas, grandes espelhos a multiplicar os raios de luz e objetos, que se achavam na sala davam belissimo aspecto èquele ambiente. Eu senti uns ares dos bons hot sis da Europa: recordei-me do confortá'cl é do bom gosto, que neles se encontram. ${ }^{12}$

$\mathrm{Na}$ sua estada, comportou-se como um turista moderno: passeou pelas ruas notando o progresso da paulicéia, fez excursões aos arrabaldes, visitando a pitoresca Penha, o Ipiranga, o marco da Independência e, obviamente, a Academia de Direito do Largo São Francisco, onde havia se formado. 
Ao voltar à Corte, desejou levar alguns presentes a vários amiges, como "sinais de lembrança.". Assim, foi à chácara da Exma. Sra. Dona Veridiana comprar algumas plantas raras; da Casa Garraux escolheu livros; na do Livro Verde, uns artefatos alemāes para servirem de enfeites de mesa; e da loja Dolivaes, diversas fotografias. ${ }^{12}$

\section{CONSIDERAÇÕES FINAIS}

Pelos motivos decorrentes do desenvolvimento urbano do Rio de Janeiro, a partir do início do século XIX, esta cidade conheceu primeiro os hotéis de categoria. A partir da década de 1870, entretanto, estava em franco crescimento a lavoura cafecira no oeste paulista e o rapido crescimento da capital de Sāo Paulo, devido às novas condiçōes econômicas, fez proliferar os empregos na cidade, tornando possível o aumento de uma classe média, pragmática e novidadeira que, poderosa economicamente, acabou se utilizando dos novos serviços oferecidos, dentre os quais os hoteleiros. Ligados diretamente ao fenômeno do desenvolvimento urbano, os hotéis do Rio e de São Paulo já no seu nascedouro procuraram diversificar suas possibilidades para atender às novas exigências, que não eram mais as do tropeiro, mas as de uma clientela cujo grande esforço consistia em compensar o atraso dos tempos coloniais com uma nova postura, moldada ao gosto europeu.

\section{REFERÊNCIAS BIBLIOGRÁFICAS}

1. LUCCOCK, John. Notas sobre o Rio de Janciro e partes meridionais do Brasil. Beto Horizonte: Itatiaia; São Paulo: EIIUSPP. 1975. p. 73.

2. KIDOER, Daniel P. Reminiscências de viagens e permanências nas preníncius do sul do Brasil. Belo Horizonte: Itatiaia: São Paulo: EDIJSP. 1980. p.89.

3. ALMANAK ADMINISTRATIV(). MERCANTJL, E: INI)USTRIAL I)A (CORTE: E: PROVINCIA DO RIO DE JANEIIRO PARA O ANNO DE 1849.p.353-4.

4. ALMANAK ADMINISTRATIVO, MERCANTIL. E INDUSTRIAI. IDA PROVÍNCIA DE SÃO PAULO - 1858.p.412.

5. AJ MANAK DE LAEMMERT PARA 1859. p. 106.660.697.

6. ALMANAK ADMINISTRATIVO. MERCANTH. E INDUSTRIAI. DA CORTE, E PROVÍNCIA DO RIO DE JANEIRO PARA O ANNO DE 1875. Para São Paulo. os dados são de MARQUES. Ahilio A. S. Indicador de Säo Paulo: administrativo, judicial, industrial, profissional e commercial para o unno de 1878 . Sảo Paulo: Ed. fac-similar da Imprensa Oticial do Estado/Arquivo do Estado. 1983.

7. FREITAS. Affonso Antonio de. Trudiçêes e reminiscências paulistanas. São Pauło: Governo do Estado. 1978. p.51-52.

8. HOUSSAY. Fréderic apud BRUNO. Ernani Silva. Fistória e tradiçùes de Sáo Paulo. São Paulo: Hucitec/Preteitura Municipal de São Paule. 1984. p. 694.

9. RENAUI.T. I)elsn. O dia-a-dia no Rio de Junciro segundo os jomais 18 -11-1884. Rin de Janeiro: Civilização Brasileira: Brasília: IN\} .. 19882. pp.102.14.5.

10. ALMANAK LAFMMERT PARA 1847

11. KOSERITZ. Carl von. Imagens do Brasil. Belo Horizonte: Itatiaia: São Paulo: EDUSP. 1980. p. 256.

12. DINIZ. Firmo de Albuquerque (Június). Vockas de viagem. São Paulo: Conerno do Estado. 1978. p. 29.119. 